\title{
Evaluation of QTc Value and Relation Between QTc Interval and Cardiovascular Risk Factors in Obese Children
}

\author{
Esra Akyuz Ozkan ${ }^{1}$, Hashem E. Khosroshahi ${ }^{2}$, Halil Ibrahim Serin ${ }^{3}$, Zeynep Tuba Ozdemir ${ }^{4}$, \\ Mahmut Kilic ${ }^{5}$, U. Aliye Gecit ${ }^{1}$, Meral Ekim ${ }^{6}$ \\ ${ }^{1}$ Department of Pediatrics, Bozok University Medical Faculty, Yozgat, Turkey \\ ${ }^{2}$ Department of Pediatric Cardiology, Bozok University Medical Faculty, Yozgat, Turkey \\ ${ }^{3}$ Department of Radiology, Bozok University Medical Faculty, Yozgat, Turkey \\ ${ }^{4}$ Department of Internal Medicine, Bozok University Medical Faculty, Yozgat, Turkey \\ ${ }^{5}$ Department of Public Health, Bozok University Medical Faculty, Yozgat, Turkey \\ ${ }^{6}$ Department of Biochemistry, Bozok University Medical Faculty, Yozgat, Turkey
}

\section{Email address:}

uzdresra@gmail.com (E. A. Ozkan)

\section{To cite this article:}

Esra Akyuz Ozkan, Hashem E. Khosroshahi, Halil Ibrahim Serin, Zeynep Tuba Ozdemir, Mahmut Kilic, U. Aliye Gecit, Meral Ekim. Evaluation of QTc Value and Relation Between QTc Interval and Cardiovascular Risk Factors in Obese Children. American Journal of Health Research. Vol. 3, No. 3, 2015, pp. 194-197. doi: 10.11648/j.ajhr.20150303.25

\begin{abstract}
Background: Obesity has a risk factor for sudden cardiac death, because of the tendency to develop arrhythmias. Delay in cardiac repolarization is reflected as QTc prolongation on electrocardiogram. The aim of this study was to investigate QTc interval in obese children and assess the relation between cardiac risk factors and QTc interval. Materials and Methods: Forty five obese children whose body mass index (BMI) persentil was $>\% 95^{\text {th }}$ and eighty seven control group were enrolled in this study. QTc was derived using Bazett's Formula. Results: Mean QTc value was found significantly longer in obese children $(413.89 \pm 23.27 \mathrm{~ms})$ than control group $(398.95 \pm 24.28 \mathrm{~ms})(p=0,001)$ and also prolonged QTc frequency was more than six times in obese (\% 15.6) than control group (\%2.4). BMI, systolic and diastolic BP, total cholesterol, triglyceride, low-density lipoprotein (LDL), fasting glucose, insulin, left ventricular mass (LVM) and carotid intima media thickness (CIMT) were significantly higher and high-density lipoprotein (HDL) levels and HOMA-IR values were lower in obese group compared with the controls. There was no correlation between QTc, metabolic parameters, systolic and diastolic BP, BMI, LVM and CIMT in obese group. Conclusion: QTc prolongation can be seen more common in obese children and may result in sudden death. So obese children must be followed closely regarding QTc interval.
\end{abstract}

Keywords: Cardiovascular Risk Factors, Carotid Intima-Media Thickness, Children, Obesity, QTc Interval

\section{Introduction}

Obesity is an independent risk factor for ventricular arrhythmia $(1,2)$. As a result of the metabolic and physiological changes, cardiovascular system is affected in obese individuals. It is known that these patients have a risk in terms of cardiac disease. Besides the risk of coronary artery disease, changes in myocardial repolarization and prolongation of the QTc and QTD value also have been showed in obese adults $(3,4)$.

The causes of QTc prolongation include the congenital long QT syndromes, electrolyte disturbances (hypokalemia, hypomagnesemia, hypocalcemia), some drugs such as anti-arrhythmic drugs, phenothiazines, tricyclic antidepressants, erythromycin, pentamidine, and certain anti-malarials, hypothyroidism, central nervous system lesions, severe bradycardia, mitral valve prolapse, acute myocardial infarction $(5,6,7)$.

The aim of this study was to investigate QTc values and assess the relation of metabolic risk factors, systolic and diastolic BP (blood pressure), LVM (left ventricular mass), BMI (body mass index), CIMT (carotid intima media thickness) with QTc interval in obese children.

\section{Materials and Methods}

Ethics approval and informed consent of the parents and patients were obtained before entering the study and selected 
randomly from outpatient population of the pediatric department of our hospital. The control group was selected among those normal children of the same department who did not have any cardiac symptoms. Patients aged 6-16 years with a diagnosis of exogenous obesity were enrolled in this study. The BMI of all children was calculated as the individual's body mass divided by the square of their height. Obesity was defined as a BMI exceeding $95^{\text {th }}$ percentile $(8,9)$.

A total of 45 exogenous obese patients (19 male and 26 female, mean age $11.14 \pm 2.98$ years, mean BMI $(26.64 \pm 3.93$ $\mathrm{kg} / \mathrm{m}^{2}$ ) and 87 healthy controls ( 44 male, 43 female, mean age $10.8 \pm 3.13$ years, mean BMI 18.12 \pm 3.47$)$ were included in the study. Patients who had coronary heart disease, idiopathic or secondary cardiomyopathies, valvular stenosis, pericardial disease or congenital heart disease, mitral valve prolapse and receiving drugs that might affect ventricular repolarization were excluded from the study.

After routine physical examination, a resting 12-lead electrocardiogram with a rhythm strip was recorded. This standard 12-lead electrocardiogram was performed with a paper speed of $25 \mathrm{~mm} / \mathrm{sec}$ and amplitude of $10 \mathrm{~mm} / \mathrm{mV}$; 5 consecutive beats were evaluated on lead II rhythm strip. The QT interval was taken as the value from the beginning of the QRS complex to the end of the down slope of the $T$ wave. The QTc for the previous cardiac R-R cycle length was calculated according to Bazett's formula (10) and QTc $>440$ ms was considered abnormally prolonged, according to the commonly used criteria (11).

Echocardiographic assessments were performed by a single pediatric cardiologist. M-mode and two-dimensional transthoracic echocardiograms were obtained and left ventricular mass (LVM) was calculated using the formula of Devereux et al (12).
The carotid artery ultrasound performed by the same radiologist, according to the recommendations of the American Society of Echocardiography Carotid Intima-Media Thickness Task Force (13).

After 12-hour fasting, the blood samples of the patients were measured for glucose, insulin, triglyceride, total cholesterol, high-density lipoprotein (HDL) and low-density lipoprotein (LDL). Insulin resistance was calculated by a homeostasis model assessment-IR (HOMA-IR) index (fasting insulin x fasting glucose / 22.5), as described by Matthews et al (14). Serum potassium, magnesium and calcium levels were obtained in the fasting state on the same day that the electrocardiograms and echocardiograms were performed.

Statistical analyse

The statistical analyses were carried out by Statistical Package for Social Sciences (SPSS). Variables were expressed as mean \pm SD. Comparisons of variables were performed using unpaired Student $t$ test and fisher exact test. Bivariate associations of the variables were assessed using Pearson's correlation coefficients and $p$ value $<0.05$ was considered indicate statistical significance.

\section{Results}

BMI, systolic and diastolic BP, total cholesterol, triglyceride, LDL, fasting glucose, insulin levels were significantly higher and HDL levels lower in obese group compared with the controls. The control group had lower HOMA-IR values than obese groups. The characteristics of the patients and healthy controls are listed in Table 1. LVM and CIMT were higher in obese group than controls $(p<0.005)$.

Table 1. Clinical and laboratory features of healthy controls and obese children.

\begin{tabular}{llll}
\hline \multirow{2}{*}{ Variable } & Obese children & Healthy controls & $\boldsymbol{p}$ value \\
\cline { 2 - 3 } & $\mathbf{4 5}(\mathbf{M} / \mathbf{F}=\mathbf{1 9 / 2 6})$ & $\mathbf{8 7}(\mathbf{M} / \mathbf{F}=\mathbf{4 4} / \mathbf{4 3})$ & 0.879 \\
\hline Age (years) & $11.22 \pm 3.05$ & $11.14 \pm 2.98$ & $0.000^{* *}$ \\
Body mass index $\left(\mathrm{kg} / \mathrm{m}^{2}\right)$ & $26.64 \pm 3.93$ & $18.12 \pm 3.47$ & $0.000^{* *}$ \\
Systolic BP (mm Hg) & $114.5 \pm 11.25$ & $102 \pm 15.72$ & $0.001^{* *}$ \\
Diastolic BP (mm Hg) & $68.88 \pm 7.85$ & $63.77 \pm 7.43$ & 0.65 \\
Glucose (mg/dL) & $89.19 \pm 7.19$ & $88.45 \pm 9.13$ & $0.000^{* *}$ \\
Triglyceride (mg/dL) & $119.39 \pm 53$ & $84.88 \pm 32$ & $0.005^{* *}$ \\
Total cholesterol (mg/dL) & $172.70 \pm 38$ & $152.49 \pm 29$ & $0.039^{*}$ \\
High-density lipoprotein (mg/dL) & $42.78 \pm 6.55$ & $46.44 \pm 10.56$ & $0.008^{* *}$ \\
Low-density lipoprotein (mg/dL) & $103.82 \pm 31.91$ & $88.51 \pm 24.58$ & $0.000^{* *}$ \\
Insulin (uIU/mL) & $13.13 \pm 7.93$ & $7.40 \pm 5.54$ & $0.000^{* *}$ \\
HOMA-IR & $3.92 \pm 1.85$ & $1.45 \pm 1.02$ & $0.000^{* *}$ \\
CIMT (mm) & $0.541 \pm 0.021$ & $0.352 \pm 0.012$ & $0.007^{* *}$ \\
Left ventricular mass (g) & $63.72 \pm 16.80$ & $56.49 \pm 12.37$ & $0.001^{* *}$ \\
QTc (msn) & $413.89 \pm 23.26$ & $398.95 \pm 24.28$ & \\
\hline
\end{tabular}

* Statistically significant $(p<0.05),{ }^{*}$ Statistically significant $(p<0.01)$.

QTc interval was longer in obese children $(p=0.001)$ (Table $1)$. The ratio of prolonged QT interval in obese $(15.6 \%)$ was six times more than non obese $(2.4 \%)$. Although the number of the children with prolonged QT interval was less ( 9 children) this was statistically significant (Table 2). The mean QT interval was found to be different in obese and non-obese $(p<0.05)$. The mean QT interval was found higher in children with normal QT interval in obese than non-obese children (mean difference $=8.84)(p<0.05)$. But the mean QT interval of children with prolonged QT interval; was not found statically significant in obese and non-obese (mean difference $=3.99)($ Table 3$)$. This result may be due to less number of children with prolonged QT interval (9 children). 
Table 2. The evaluation of QT interval in obese and non-obese children

\begin{tabular}{llll}
\hline \multirow{2}{*}{ GROUPS } & \multicolumn{2}{l}{ QT interval } & \\
\cline { 2 - 4 } & Normal & Prolonged & Total \\
\cline { 2 - 4 } & $\mathbf{N}(\%)$ & $\mathbf{N}(\%)$ & $\mathbf{N}(\%)$ \\
\hline OBESE & $38(84.4 \%)$ & $7(15.6 \%)$ & $45(100.0 \%)$ \\
NON-OBESE & $85(97.6 \%)$ & $2(2.4 \%)$ & $87(100.0 \%)$ \\
TOTAL & $123(91.7 \%)$ & $9(8.3 \%)$ & $132(100.0 \%)$ \\
\hline
\end{tabular}

Fisher's Exact Test $p<0,05$

Table 3. Prolonged and normal QT intervals in obese and non-obese children.

\begin{tabular}{|c|c|c|c|c|}
\hline \multirow{3}{*}{ GROUPS } & \multirow{3}{*}{$\mathbf{n}$} & \multicolumn{3}{|l|}{ QT interval } \\
\hline & & $\begin{array}{l}\text { Normal } \\
(n=123)\end{array}$ & $\begin{array}{l}\text { Prolonged } \\
(n=9)\end{array}$ & Total $(n=132)$ \\
\hline & & Mean & Mean & Mean \\
\hline OBESE & 45 & $406.60 \pm 15.81$ & $453.47 \pm 16.25$ & $413.89 \pm 23.27$ \\
\hline NON-OBESE & 87 & $397.76 \pm 23.25$ & $449.48 \pm 9.48$ & $398.95 \pm 24.28$ \\
\hline \multirow[t]{2}{*}{ TOTAL } & 132 & $400.49 \pm 21.56$ & $452.58 \pm 14.57$ & $404.04 \pm 24.89$ \\
\hline & $\mathrm{t}, \mathrm{p}^{\mathrm{a}}$ & $2.42,0.018$ & $0.83,0.428$ & $3.09,0.002$ \\
\hline
\end{tabular}

${ }^{\mathrm{a}} \mathrm{t}$ student test, Sig. (2-tailed) by column groups.

There was no correlation between cholesterols, glucose, and insulin, HOMA-IR, LVM, CIMT and QT.

\section{Discussion}

The risk of coronary artery disease and arrhythmias increases in obesity. It has been reported that disorders in sinus node automaticity in obese and can result with sinus arrhythmia, bradycardia, sinus block, supraventricular and ventricular ectopic beats and intraventricular block could be obvious (15).

In current study we reported that mean QTc value was higher in obese children than control group $(p=0,001)$.

There has been shown that prolonged QTc interval leads to increases risk of ventricular arrhythmias and QTc interval could be shortening with weight loss (16). In contrast to this study, some other studies showed that QTc intervals does not change with weight loss even longer $(17,18)$. According to other reports there was no association between obesity and prolongation of the QTc interval $(19,20)$.

In a study reported by Olivares-Lopez et al mean QTc and mean QTc dispersion values were found significantly longer/greater in 30 overweight or obese children than in 30 healthy controls (21). Girola et al (22) and Bilora et al (23) could not show relation between obesity and delayed ventricular repolarization.

Also in current study we found that QTc frequency was six times more in obese group (\%15.6) than controls (\%2.4) and this was statistically significant (Table 2).

In present study there was no correlation between QTc and LVM in obese children $(p=0.63)$. Mukerji et al found positively correlation between QT, LVM and systemic BP and in multivariate regression analyse LVM was the only predictor factor for QT lacking systemic hypertension in adults (24). Increased LVM is a good predictor to determine the risk of cardiovascular disease in obese persons $(25,26)$. Incidence of ventricular ectopic beats increases in patients with increased LVM (27). Although the exact cause is unknown, changes in myocardial metabolism, cardiac hypertrophy and changes in cardiac autonomic innervations causes repolarization abnormalities in obese patients (28).

In current study we couldn't show any correlation between QTc and BMI $(p=0,71)$. Seyfeli et al showed that BMI positively correlated with QTc (29). Arslan E et al reported that QTc positively correlated with BMI and waist circumference (30).

In our study there was no statistically significant relation between QTc and metabolic parameters such as insulin resistance, dyslipidemia and systolic and diastolic BP.

Festa et al (31) found a significant relationship between QTc interval and carotid atherosclerosis in nondiabetic subjects. These authors also suggested the QTc interval as a marker of undetected atherosclerotic disease. We couldn't find any correlation between CIMT and QT $(p=0.794)$. Guven et al reported that QTc was found to be significantly affected by CIMT, chronologic age and HDL-C (32).

In conclusion, QTc prolongation can be seen more common in obese children and may result in sudden death. So obese children must be followed closely regarding QTc interval. The prolongation of QTc interval indicates impaired ventricular repolarization and that these changes began during childhood. The prevalence of childhood obesity increasing gradually worldwide; the importance of early identification and prevention of the disease is understood better.

\section{Study Limitations}

Although the number of children in this study was enough for statistical analyses, further investigations with larger number of obese children is recommended.

\section{References}

[1] Messerli FH, Nunez BD, Ventura HO, Snyder DW. Overweight and sudden death. Increased ventricular ectopy in cardiopathy of obesity. Arch Intern Med 1987; 147: 1725-1728.

[2] Kannel WB, Plehn JF, Cupples LA. Cardiac failure and sudden death in the Framingham Study. Am Heart J. 1988; 115: 869-875.

[3] Baduini G, Calcaterra G, Rossi P. Changes of left ventricular contractility in alternating left bundle branch block. Eur J Cardiol 1981; 12: 207-213.

[4] Rahko PS, Shaver JA, Salerni R. Evaluation of mechanical events and systolic function in dilated cardiomyopathy: comparison between patients with and without left bundle branch block. Acta Cardiol 1988; 43: 179-184.

[5] Moss AJ. Measurement of the QT interval and the risk associated with QTc interval prolongation: a review. Am J Cardiol 1993; 72: 23B-25B.

[6] Malik M, Batchvarov VN. Measurement, interpretation and clinical potential of QT dispersion. J Am Coll Cardiol 2000; 36: 1749-1766. 
[7] Goldenberg I, Moss AJ. Long QT syndrome. J Am Coll Cardiol 2008; 51: 2291-2300.

[8] Kuczmarski RJ, Ogden CL, Guo SS, Grummer-Strawn LM, Flegal KM, Mei Z, Wei R, Curtin LR, Roche AF, Johnson CL. 2000 CDC Growth Charts for the United States:methods and development. Vital Health Stat 11. 2002; 246: 1-190.

[9] Shriver LH, Harrist AW, Hubbs-Tait L, Topham G, Page M, Barrett A. Weightstatus, physical activity, and fitness among third-grade rural children. J SchHealth 2011; 81: 536-544.

[10] Bazett HC. An analysis of the time relationships of electrocardiograms Heart 1920; 7: 353-357.

[11] Schwartz PJ, Stramba-Badiale M, Segantini A, Austoni P, Bosi G, Giorgetti R, Grancini F, Marni ED, Perticone F, Rosti D, Salice P. Prolongation of the QT interval and the sudden infant death syndrome. N Engl J Med 1998; 338: 1709-1714.

[12] Devereux RB, Alonso DR, Lutas EM, Gottlieb GJ, Campo E, Sachs I, Reichek N. Echocardiographic assessment of left ventricular hypertrophy: comparison to necropsy findings. Am J Cardiol 1986; 57: 450-458.

[13] Stein JH, Korcarz CE, Hurst RT, Lonn E, Kendall CB, Mohler ER, Najjar SS, Rembold CM, Post WS; American Society of Echocardiography Carotid Intima-Media Thickness Task Force. Use of carotid ultrasound to identify subclinical vascular disease and evaluate cardiovascular disease risk: a consensus statement from the American Society of Echocardiography Carotid Intima-Media Thickness Task Force.Endorsed by the Society for Vascular Medicine. J Am Soc Echocardiogr 2008; 21: 93-111.

[14] Matthews DR, Hosker JP, Rudenski AS, Naylor BA, Treacher DF, Turner RC. Homeostasis model assessment: insulin resistance and beta-cell function from fasting plasma glucose and insulin concentrations in man. Diabetologia 1985; 28: 412-419.

[15] Shaver JA, Rahko PS, Grines CL, Boudoulas H, Wooley CF. Effects of left bundle branch block on the events of the cardiac cycle. Acta Cardiol 1988; 43: 459-467.

[16] Weissler AM, O'Neill WW, Sohn YH, Stack RS, Chew PC, Reed AH. Prognostic significance of systolic time intervals after recovery from myocardialinfarction. Am J Cardiol 1981; 48: 995-1002.

[17] Xiao HB, Lee CH, Gibson DG. Effect of left bundle branch block on diastolic function in dilated cardiomyopathy. Br Heart J 1991; 66: 443-447.

[18] Giannuzzi P, Imparato A, Temporelli PL, de Vito F, Silva PL, Scapellato F, Giordano A. Doppler-derived mitral deceleration time of early filling as a strong predictor of pulmonary capillary wedge pressure in postinfarction patients with left ventricular systolic dysfunction. J Am Coll Cardiol 1994; 23: 1630-1637.
[19] Thomas JD, Weyman AE. Echocardiographic Doppler evaluation of left ventricular diastolic function. Physics and physiology. Circulation 1991; 84: 977-990.

[20] Xiao HB, Brecker SJ, Gibson DG. Differing effects of right ventricular pacing and left bundle branch block on left ventricular function. Br Heart J 1993; 69: 1666-1673.

[21] Olivares López JL, Vázquez Olivares M, Fleta, Zaragozano J Moreno Aznar LA, Bueno Sánchez M. Electrocardiographic and echocardiographic findings in children with overweight and obesity. Med Clin (Barc) 2005; 125: 93-94.

[22] Girola A, Enrini R, Garbetta F, Tufano A, Caviezel F. QT dispersion in uncomplicated human obesity. Obes Res 2001; 9: 71-77.

[23] Bilora F, Vettore G, Barbata A, Pastorello M, Petrobelli F, San Lorenzo I. Electrocardiographic findings in obese subjects. Minerva Gastroenterol Dietol 1999; 45: 193-197.

[24] Mukerji R, Terry BE, Fresen JL, Petruc M, Govindarajan G, Albert MA. Relation of left ventricular mass to QTc in normotensive severely obese patients. Obesity (Silver Spring) 2012; 20: 1950-1954.

[25] Schneider JF, Thomas HE Jr, Sorlie P, Kreger BE, McNamara PM, Kannel WB. Comparative features of newly acquired left and right bundle branch block in the general population: the Framingham study. Am J Cardiol 1981; 47: 931-940.

[26] Fahy GJ, Pinski SL, Miller DP, McCabe N, Pye C, Walsh MJ, Robinson K. Naturalhistory of isolated bundle branch block. Am J Cardiol 1996; 77: 1185-1190.

[27] Grossman W. Diastolic dysfunction in congestive heart failure. N Engl J Med 1991; 325: 1557-1564.

[28] Wyndham CR, Smith T, Meeran MK, Mammana R, Levitsky S, Rosen KM. Epicardial activation in patients with left bundle branch block. Circulation 1980; 61: 696-703.

[29] Seyfeli E, Duru M, Kuvandik G, Kaya H, Yalcin F. Effect of obesity on P-wave dispersion and QT dispersion in women. Int J Obes (Lond) 2006; 30: 957-961.

[30] Arslan E, Yiğiner O, Yavaşoğlu I, Ozçelik F, Kardeşoğlu E, Nalbant S. Effect of uncomplicated obesity on QT interval in young men. Pol Arch Med Wewn 2010; 120: 209-213.

[31] Festa A, D'Agostino R Jr, Rautaharju P, O'Leary DH, Rewers M, Mykkänen L, Haffner SM. Is QT interval a marker of subclinical atherosclerosis in nondiabeticsubjects? The Insulin Resistance Atherosclerosis Study (IRAS). Stroke 1999; 30: 1566-1571.

[32] Güven A, Özgen T, Güngör O, Aydın M, Baysal K. Association between the corrected QT interval and carotid artery intima-media thickness in obese children. J Clin Res Pediatr Endocrinol 2010; 2: 21-27. 